\title{
The Relationship between Emerging Forms of Bullying and Depression among Secondary Schools Students in Bungoma County, Kenya
}

\author{
Jane Ingado Misigo $^{1 *}$, Dr. James Kay ${ }^{2}$, Dr. Esther Kibor ${ }^{3}$
}

${ }^{1} \mathrm{PhD}$ Candidate in Counseling Psychology, Kabarak University, Kenya

${ }^{2}$ Lecturer, Department of Educational Psychology, Kabarak University, Kenya

${ }^{3}$ Lecturer, Department of Religious Studies, Kabarak University, Kenya

\begin{abstract}
DOI: $10.36348 /$ SJHSS.2019.v04i10.001
| Received: 13.09.2019 | Accepted: 20.09.2019 | Published: 27.10.2019
\end{abstract}

*Corresponding author: Jane Ingado Misigo

\section{Abstract}

The purpose of the study was to investigate the relationship between emerging forms of bullying and depression among students in Bungoma County, Kenya. The Social-Ecological Theory and Psychosocial Theory guided the study. The research population was 29,040 Form Three students. Deputy Principals and Guidance and Counseling teachers from 360 secondary schools were the study respondents. A sample size of 399 students was drawn from boys, girls and co-education schools. Form Three Students were randomly selected from the sampled schools. The study adopted a cross-sectional research design using a mixed-method approach. Both qualitative and quantitative data was collected concurrently. Stratified random sampling and simple random sampling was used to sample schools and students, respectively. A pilot study was conducted on the 30 Form Three students selected from three categories of secondary schools in Bungoma County. Data was collected using a self-response questionnaire and interview schedule guide. Quantitative data was analyzed using descriptive statistics, namely mean, standard deviation and percentages we re used to describe data. Inferential statistics such as Pearson Correlation statistics, ANOVA were used to test the significance of the stated hypothesis at the alpha level $(\alpha=0.05)$. The qualitative data was thematically analyzed based on the objective and presented in a prose form. All analysis was done using the statistical package for social sciences (SPSS) version 21.0. The findings revealed that there was a positive relationship between emerging forms of bullying and depression $(\mathrm{R} 2=.304(30.4 \%)$.

Keywords: Bullying, depression, Secondary Schools, Bungoma County, Kenya.

Copyright @ 2019: This is an open-access article distributed under the terms of the Creative Commons Attribution license which permits unrestricted use, distribution, and reproduction in any medium for non-commercial use (NonCommercial, or CC-BY-NC) provided the original author and source are credited.

\section{INTRODUCTION}

In almost all societies, a significant number of school students have been survivors of school bullying. Fleming and Jacobsen, 2010 found out that in the U.S, approximately $30 \%$ of students who were involved in bullying were either perpetrators $(13.0 \%)$, victims $(10.6 \%)$ or bullying/victims $(6.7 \%)$ of some type of bullying. In Latin America, the prevalence of bullying ranged between $40-50 \%$. Large scale surveys carried out in individual countries have also reported bullying rates of between 4-9 per cent in western countries and 47-73 per cent in developing countries [1]. A review of studies done by Chan and Wog [2] the prevalence of bullying victimization ranged from $2 \%$ to $66 \%$ in China, $20 \%$ to $62 \%$ in studies done in Hong Kong, $24 \%$ to $50 \%$ Taiwan. This statistics indicates that bullying among adolescents is a major concern in both developed and developing countries. Kenya being a developing country, a similar study was important as it assisted in reporting on social-cultural similarities or differences if any.

Farrington and Baldry [3] indicated that while some socio-demographic features like age, race, gender, and one's ethnicity are significant predictors of bullying and behaviour among adolescents. Baldry noted that bullying seriously impacts on students' personal sense of safety and academic performance. In a study by National Centre for Educational Statistics [4] in the U.S, it was discovered that $33 \%$ of high school going students stated that they were bullied at school at least on one day on because they felt unsafe at school. Among the students who reported being bullied, $13 \%$ were made fun of, called names or insulted, $12 \%$ were the subject of rumours, $5 \%$ were pushed, shoved, tripped or spat on, and $5 \%$ were excluded from activities on purpose. In an effort to address bullying in schools, Centre for 
Disease Control in America has made bullying prevention a national priority and aims at increasing safety in school and advocates for adoption and implementation of the anti-bullying policies in the coming decade [5]. This prompted the study to establish the extent of bullying among adolescents in secondary school.

\section{Problem Statement}

Forms of bullying have also shifted from physical violence, stealing, and washing clothes of senior students to social exclusion, threats, sexual and ethnic harassment, public humiliation, destruction of the targeted students' property, stalking and to most sophisticated such as cyberbullying texting through social media, emails and social exclusion. Despite the growing recognition and entrenchment of the vice in schools, its influence on the adolescents' development has not received adequate attention. However, there hasn't been much documentation on the relationship between the new forms of bullying and youth psychosocial adjustment. Current studies indicate that Kenya is among countries with the highest level of bullying with a prevalence of 43-74 \% among adolescents aged 13 to 17 years. Despite government's efforts to eradicate the vice, the presidential committee on the discipline of students recommended that the Kamunge recommendation on Guidance and counselling had not been implemented in most schools, Ministry of Education Science and Technology 2001. Basic Education act 2013 also spells out clearly that administrators should provide a secure physical and psychological social setting for the learners, yet bullying is still reported. In particular, Bungoma County has experienced several incidences of indiscipline cases associated with bullying among students in secondary schools. Between 2017 and July 2018, there were twelve cases of violent acts of behaviour related to bullying. The County Education office had sufficient evidence of bullying in schools and other violent behaviours such as fighting, rioting and sexual violence [6]. The fact that there is a dearth of documented studies on the relationship between bullying and depression implies that the issue of bullying has not been adequately addressed in empirical research in Bungoma County. If this situation continues, the effects may culminate into suicide, dropout or have psychological and physical, which affects both bullies and the bullied. This presents a knowledge gap concerning the dynamics and consequences of the phenomena. It is with this background that the research examined the relationship between bullying and depression among secondary students learning in Bungoma County.

\section{LITERATURE REVIEW}

The most commonly diagnosed mental health problem among youths is depression, and it leads to devastating long-term outcomes [7]. The alarming increase in depressive symptoms during early and mid- adolescence is posing a concern not only to the western world but also in the developing countries [8]. In Germany for instance, 5.6\% of 14-17 years old adolescents showed clinically relevant symptoms of depression.

Studies have shown a correlation between forms of bullying and depression [9]. The studies revealed that depression associated with bullying results in distortion of the processing of social information, negative self-perception. Depression may impair social skills among adolescents and may cause them helpless. However, extant research has only examined the association between traditional forms of bullying and little is documented on the emerging forms of bullying and depression, especially in underdeveloped countries like Kenya.

In a different study, Dahlgvist, Landstedt, Young and Gadin [10] investigated the relationship between the dimension of sexual bullying by peers, victimization and profiles of depressive symptoms from ages 14-16 in adolescents. The study also aimed at investigating gender difference in this pathway. Results revealed that sexual name-calling was the profile that had the strongest associations to all profiles of depressive symptoms irrespective of gender. Amongst boys, name-calling was preceded by all dimensions of depressive symptoms. This study intended to assess the association between emerging forms of sexual bullying that has been under-explored and depressive symptoms among students in secondary schools in Kenya to find out whether the association was similar to documented research in other countries.

Schneider, O’Donnell, Stueve and Couller [11] evaluated the prevalence of cyberbullying and school bullying victimization and their associations with psychological distress in the USA. The study that was done among adolescent revealed that $15.8 \%$ of students reported cyberbullying, and $25.9 \%$ reported cyberbullying in the past 12 months. Controlled analysis indicated that distress (depressive symptoms, selfinjury and suicidal tendency) was highest among victims of both cyberbullying and school bullying. Adjusted odds ratio (AORs) were from 4.38 for depressive symptoms to 5.35 for suicide attempts requiring medical treatment.

In Africa, Adeoye [12] examined the influence of peer victimization on the sexual behaviour of the students with the view of finding out the relationship and ways of coping with the problems. The results showed that peer victimization contributed to the sexual behaviour of the students. Other studies done by researchers show evidence that sexual bullying exists in Kenyan institution of learning, for example [13].

In Kenya, a study by Khakasala, Ndetei, 
Mutiso, Mbwayo and Mathai [14] sought to determine the prevalence of depressive symptoms among adolescents in Nairobi public secondary schools. The researchers made a comparison between day and boarding students and identified associated factors in that population. They randomly sampled school-going adolescents from a stratified sample of 17 secondary schools out of the 49 public secondary schools in Nairobi province. The sample was stratified to take into account geographical distribution, day and boarding school, boys only, girls only and mixed coeducation school. Self-administered instruments were used to measure perceived parental behaviour and levels of depression in 1276 students. The results showed that the prevalence of clinically significant depressive symptoms was $26.4 \%$ and that students in boarding schools had more clinically significant depressive symptoms compared to day schooling students. The results also showed positive correlations between scores for depression and perceived rejecting parental behaviour $(\mathrm{P}<0.001)$. This study, however, did not deal with the relationship between bullying and depression among the secondary school students, the knowledge in the gap that the current study attempted to fill.

\section{METHODOLOGY}

This study adopted a cross-sectional research design using mixed method research methodologies to collect information. The target population of the study comprised of 106,559 students from all public schools in Bungoma County. The population consisted of 54,798 females and 51,761 male students. The accessible population under study was 29,040 Form Three students. Purposive sampling was used in this study, as it is effective in studying subjects that possess specific characteristics that are required in the study hence Form Threes. To select a specific sample from the population of Form Three students who took part in the study, simple random sampling was used to select the student respondents. Using the Krejcie and Morgan
[15] formula 399 students in Form three were obtained and was assumed to be a representative of the total population of 29,040 Form three students. Simple random sampling was employed to get 11 students per school involved in the study. One Guidance and counselling teachers were purposively selected to the sampled schools. Data for this study was obtained using items on a scale; thus, Students' questionnaire, Deputy Principal and Teacher Counselor Interview schedule guide was used. A pilot study was carried out to assess the reliability of the instruments. This was done in 3 secondary schools, 3 Guidance and counselling teachers, and 3 Deputy Principles were involved. Data was coded scored accurately and transcribed into the computer for analysis using the Statistical Package for Social Sciences (SPSS) Version 21. Items for the students' questionnaires on emerging forms of bullying and psychosocial adjustment were scored on a scale of 5-point Likert Scale.

\section{FINDINGS AND DATA ANAL YSIS}

Multiple regression analysis was conducted to ascertain which form of bullying substantially predicted depression. In model 1, cyberbullying, stalking, sexual bullying and social exclusion were entered. To establish the relationship between the emerging forms of bullying and depression for secondary schools students in Bungoma County, a multiple regression analysis was used. The regression model was of the form where:

$D$ is the level of depression; is the level of cyberbullying, is the level of social exclusion, is the level of sexual bullying, is the level of stalking and is the constant of the regression equation.

To assess the amount of variation in depression that can be explained by the emerging forms of bullying, the coefficient of determination was used. The results are presented in Table 14.

Table-1: Model Summary of Predicting Depression

\begin{tabular}{|l|c|l|l|l|}
\hline Mode & R & R Square & Adjusted R Square & Std. Error of the Estimate \\
\hline 1 & $.551^{\mathrm{a}}$ & .304 & .296 & 8.16410 \\
\hline \multicolumn{4}{|c|}{ Predictors: (Constant), Cyberbullying, stalking } \\
\hline
\end{tabular}

The results indicate that the coefficient of determination $R^{2}=0.304$ was obtained. This indicated that $30.4 \%$ of the variation in levels of depression for the sample of 399 students surveyed could be explained by the changes in the levels of cyberbullying and stalking, while $69.6 \%$ remains unexplained.
In assessing whether the model with the two independent variables can significantly predict the behaviour outcome, the $F$-statistic from the ANOVA was used, and the results are reported in Table-2.

Table-2: Summary of ANOVA tests for Depression Model $(N=399)$

\begin{tabular}{|l|l|l|l|l|c|c|}
\hline \multicolumn{2}{|c|}{ Model } & Sum of Squares & Df & Mean Square & F & Sig. \\
\hline \multirow{2}{*}{1} & Regression & 11446.31 & 2 & 2861.58 & 42.93 & .000 \\
\cline { 2 - 7 } & Residual & 26261.11 & 396 & 66.65 & & \\
\cline { 2 - 7 } & Total & 37707.42 & 398 & & & \\
\hline \multicolumn{7}{|c|}{ Predictors: (Constant), Cyberbullying, stalking } \\
\end{tabular}


In the findings presented in Table-2, $F$ statistics results reveal that the independent variables; cyberbullying and stalking significantly predict the levels of depression among the secondary school students in Bungoma County $\left(F_{(4,394)}=42.933, p<\right.$ 0.05). According to Geller (2009), ANOVA is used to test the significance of variation in the dependent variable that can be attributed to the regression of one or more independent variables. Employment of this statistical procedure produces a calculated $F$ value that is compared to a critical $F$ value for a particular level of statistical probability. Obtaining a significant $F$ value indicates that the results of the regression are indeed true and not the consequence of chance.

In assessing the significance of the multiple regression coefficients in the model, the $t$-test for regression coefficients and the standardized beta values were used. The unstandardized regression coefficients, the standardized beta coefficients and $t$ test values are presented in Table- 3 .

Table-3: Coefficients of the relationship between Emerging Forms of Bullying and Depressio $(N=399)$

\begin{tabular}{|c|c|c|c|c|c|}
\hline Model & Unstandardized Coefficients & B Std Error & Standardized Coefficients Beta & $\boldsymbol{t}$ & Sig. \\
\hline (Constant) & 9.927 & 1.610 & & 6.166 & .000 \\
\hline Cyberbullying & .202 & .077 & .154 & 2.612 & .009 \\
\hline Stalking & .168 & .051 & .211 & 3.320 & .001 \\
\hline
\end{tabular}

To testing the statistical significance of the regression coefficients, the $t$-test together with the $p$ values were used as indicated in Table-3. In testing the significance of the cyberbullying $\left(\mathrm{X}_{1}\right)$ coefficient, $t$ value of 2.61 was obtained and since $p=0.009$, the study concluded that there the influence on the cyberbullying on the levels of depression among the secondary school students in Bungoma County was statistically significant. Likewise, the influence of stalking on the levels of depression was established to be statistically significant $(t=3.320, p=0.000)$. The study, therefore, rejected the null hypothesis. The study findings are similar to findings by Williams, Langhinrichsen-Rohling, Wornell, and Finnegan [16], who established that females who reported being victims of cyberbullying reported depressive symptoms.

\section{CONCLUSION AND RECOMMENDATION}

This study found that there was a positive relationship between the emerging forms of bullying and depression among students in Bungoma County. Specifically, the study showed that the more the students experienced any of the two emerging forms of bullying, the more they were likely to be depressed. When the effects of other predictor were held constant, staking was the major predictor of depression. This implied that during adolescence, acceptance by peers is an important aspect of their development as they individuate from their parents, so being deliberately left out has a psychological impact on their mental health. Based on the finding that cyberbullying and stalking can significantly predict the levels of depression among secondary school students in Bungoma County.

\section{RECOMMENDATION}

Based on these findings, there is a strong need for comprehensive school-based programs directed at the prevention and intervention of the emerging forms of bullying. Education about emerging forms of bullying could be integrated into the school curriculum, for example, engaging students in scholarly debates and life skills, as well as coverage of sexual bullying in formal sex education curricula.

\section{REFERENCES}

1. Juvonen, J., \& Graham, S. (2014). Bullying in schools: The power of bullies and the plight of victims. Annual review of psychology, 65, 159185.

2. Wong, D. S., Lok, D. P., Wing Lo, T., \& Ma, S. K. (2008). School bullying among Hong Kong Chinese primary schoolchildren. Youth \& Society, 40(1), 35-54.

3. Farrington, D., \& Baldry, A. (2010). Individual risk factors for school bullying. Journal of aggression, conflict and peace research, 2(1), 416.

4. Rampey, B. D., Keiper, S., Mohadjer, L., Krenzke, T., Li, J., Thornton, N., \& Hogan, J. (2016). Highlights from the US PIAAC survey of incarcerated adults: Their skills, work experience, education, and training: Program for the international assessment of adult competencies: 2014 (NCES 2016-040). US Department of Education. Washing-ton, DC: National Center for Education Statistics. Retrieved [date] from http://nces. ed. gov/pubsearch.

5. McGuire, S. (2011). US department of agriculture and US department of health and human services, dietary guidelines for americans, 2010. Washington, DC: US government printing office, January 2011.

6. Kisiang'ani, B. A. (2018). Influence of Parental Involvement on Learner Achievement in Mathematics Activities In Early Childhood Education Centers In Chwele Zone Kabuchai SubCounty Bungoma County, Kenya. Thesis, University of Nairobi.

7. Granic, I. (2016). The promise of applied video games for the prevention of anxiety and depression in youth. International Journal of 
Behavioural Development, 40(6).

8. Weichold, K., \& Blumenthal, A. (2016). Longterm effects of the life skills program IPSY on substance use: results of a 4.5-year longitudinal study. Prevention science, 17(1), 13-23.

9. Fröjd, S., Ranta, K., Kaltiala-Heino, R., \& Marttunen, M. (2011). Associations of social phobia and general anxiety with alcohol and drug use in a community sample of adolescents. Alcohol and alcoholism, 46(2), 192199.

10. Dahlqvist, H. Z., Landstedt, E., Young, R., \& Gådin, K. G. (2016). Dimensions of peer sexual harassment victimization and depressive symptoms in adolescence: A longitudinal crosslagged study in a Swedish sample. Journal of youth and adolescence, 45(5), 858-873.

11. Schneider, S. K., O'donnell, L., Stueve, A., \& Coulter, R. W. (2012). Cyberbullying, school bullying, and psychological distress: A regional census of high school students. American journal of public health, 102(1), 171-177.

12. Adeoye, H. (2013). Peer victimisations as correlates of sexual behaviour among senior secondary school Students. Procedia-Social and Behavioral Sciences, 82, 243-247.

13. Ruto, J., \& Chege, R. (2006). Violence against girls as a structural barrier to her right to and in education. Action Aid Kenya Gender Desk.

14. Khasakhala, L. I., Ndetei, D. M., Mutiso, V., Mbwayo, A. W., \& Mathai, M. (2012). The prevalence of depressive symptoms among adolescents in Nairobi public secondary schools: association with perceived maladaptive parental behaviour. African journal of psychiatry, 15(2), 106-113.

15. Krejcie, R. V., \& Morgan, D. W. (1970). Determining sample size for research activities. Educational and psychological measurement, 30(3), 607-610.

16. Williams, S. G., Langhinrichsen-Rohling, J., Wornell, C., \& Finnegan, H. (2017). Adolescents transitioning to high school: Sex differences in bullying victimization associated with depressive symptoms, suicide ideation, and suicide attempts. The Journal of School Nursing, 33(6), 467-479. 